\title{
Convivial Acts for an Ecosensual
}

\section{Labyrinth}

\section{Billinghurst, $\mathrm{H}$}

http://hdl.handle.net/10026.1/16158

10.1080/02604027.2020.1778337

World Futures

Informa UK Limited

All content in PEARL is protected by copyright law. Author manuscripts are made available in accordance with publisher policies. Please cite only the published version using the details provided on the item record or document. In the absence of an open licence (e.g. Creative Commons), permissions for further reuse of content should be sought from the publisher or author. 


\title{
Convivial Acts for an Ecosensual Labyrinth
}

Helen Billinghurst \& Phil Smith

PhilSmith: mytho.smith@btopenworld.com ; Helen Billinghurst: helenbeee@hotmail.com 20 Acre Place, Stoke, Plymouth, PL1 4QR

Title short version for running head: Convivial Acts for an Ecosensual Labyrinth

\begin{abstract}
This paper addresses queer conviviality across Crab \& Bee's 'Plymouth Labyrinth' project (2018-19); a six month activity including group walks, ritual sharings, group readings, postal art, poetry groups, site-specific dance, exhibition and making workshops. Based around convivial web-walking, the account examines how, through spinning out of collaborations and unfolding new forms, a web of work and activity was generated to support intensity and connectivity. The paper attends to queer aspects of conviviality, such as attention to unhuman partners, becoming-animal, simultaneity/plateauing in haecceity, dispersals of subjectivity and relations of threads (lines of desire) to web making.
\end{abstract}

Keywords: conviviality, web walking, fictioning, world building, haecceity

\section{Introduction}

In this paper we share some of the devices and strategies for a queer convivialising of ecosensuality that have emerged during 'Plymouth Labyrinth'; a 2018/19 project of hypersensitized walking, community participation, making, writing, exhibition and performance around Plymouth (UK). The project sought to highlight connectivity and flow across the city as a way to forge webs of convivial connections (social, ecological and geographical) to generate and disseminate immersively-sourced knowledge, and to create chains of 
spontaneous creative response and action. Crucial to this approach was a relation to things and critters that draws them in to a sensoriality that does not sharply distinguish between human and unhuman; at the same hyper-sensitizing the human participants to the unhuman. As a model for making emerged from the project, it simultaneously revealed a capacity for adaptation to other places and situations.

As part of sharing our devices and strategies it is our attention to highlight queer aspects of eco-conviviality, that include intercorporeality, attention to unhuman partners, becominganimal, haecceity, scatterings of subjectivity and relations of threads (lines of desire) to web making. These are both findings and methods of a practical research that draws from the immersive walking and body/mind thinking that is at the core of our inter-disciplinary art practices. While we share the Convivialist Manifesto's call to 'project ourselves into the future and re-appropriate our past' (Alphandéry et al 2013: 29), given current climate and ecological crisis, we are inclined to cast our net wider than 'the whole of humankind with its rich diversity of cultural traditions' (ibid: 29). Consequently, we advocate a less humancentric approach, closer to Donna Haraway’s discussions of "tentacularity" (ibid: 71) and "living and dying together well" (Ibid: 116), while attending to conviviality between species and the "chthonic powers" of the gods of the earth (ibid: 53).

\section{The Project}

'Plymouth Labyrinth' was a project we initiated in late 2018 as a way to explore and reveal hidden layers of everyday space in Plymouth. The city is a coastal community in the South West of England, with some of the poorest electoral wards in the country. For centuries it was dominated by the presence of the Royal Navy. Second World War bombing destroyed most of the centre of the city and this led to much post-war building of suburbs, many of which today are lacking in social and community space and facilities. The rapidity and eco-insensitivity of this construction led to many rivers being buried or diverted and also captured large areas of 
woodland within the built-up areas; Plymouth has more woodland within its city bounds borders than any other UK city.

In the last two decades the city has become more diverse as a result of higher rates of immigration, economic and political changes that have seen the shrinking of the Navy's influence and a more variegated culture including the comparatively late emergence of a visible LGBT presence. Higher and further education have in recent years played a significant role in the city, and there is a relatively thriving though underfunded arts scene.

Our project, 'Plymouth Labyrinth', emerged from Helen's ongoing walking in the city over the previous year, which in turn was a sideways shift within her walking of a route between her present home in Plymouth and her childhood home in Cambridge for her 'Crossing England' research project and exhibitions. In 'Plymouth Labyrinth' we set out to address spaces of exclusion, amnesia, excavation, pollution and crisis. We wanted to make art works, performances, walks, maps and guides that would help others engage and understand the marginalised terrains in the city; particularly where human and ecological abjection or nurture were knitted.

We began by addressing Plymouth as a labyrinth, drawing on the classical myth of the labyrinth $^{1}$ at Knossos, the Minotaur, and Ariadne's navigational red thread. Like Ariadne, we used red thread (later, also green and white) to explore the Labyrinthine terrain we had chosen to walk in. Threads were used to mark, bind, play, mend and disrupt, but also to render visible previously unseen connections.

We set out together to explore the 'Plymouth Labyrinth' on foot. This walking was queered by our mutual attention to the specific sensual qualities - or personalities - of each location through our shared strategy of immersive walking. We used our bodies to engage directly with trees, soils, and water; collecting and rearranging materials as we went. We got into the

\footnotetext{
1 'Labyrinth' in this context draws from the suggestion by Olaf Nicolai \& Jan Wenzel (2012) that the story of the labyrinth does not originate from a construction under Knossos, but from the bewildering structure of the city itself seen through the eyes of nomadic visitors. We chose to use this idea as a lens through which to view Plymouth and to disrupt from the city's clichéd narratives, such as those of the Spanish Armada \& the Blitz.
} 
habit of reflecting on these walks during long, convivial conversations in pubs in the evening after the walks, drawing out associations, and identifying the key images and narratives (we came to refer to these as 'fabulous images') that had emerged during each journey, as parts of a greater web of images and storylines spinning together to form and reform our navigation of the city.

During our early walks, we devised a series of light, quick 'actions' to help us to become rapidly immersed in the sites we were exploring. These began with simple activities like paddling (or swimming) in the water, breathing out to the horizon and lying on our backs in the mud to 'experience' gravity. Through this process, we came to increasingly refer to our own body/minds as forests, swamps, mud, oceans, floods, flows, evidenced by a sudden and unplanned outpouring of poetry written by Crab \& Bee in response to these encounters, which simultaneously addressed places and the sensual or desirous nature of the embodied affects they provoked; not as metaphor in which one thing stands in for another, but as a blurring of boundaries between the two. Our performance of physical actions during public readings of this poetry - scattering of ashes, whirling of sheep bones - pointed up the corporeal nature of our poetry-making.

Our experiments with woollen threads to explore connectivity became more sophisticated and developed into a taxonomy; a language of threads and colours. Our initial experiments with red threads explored lines of desire, blood circulation and carnal appetite (these turned into the game 'Hunt and Be Hunted'). Later, we found green threads were cooler, good for connecting to trees and plant-life. Later still, we used white threads to explore stillness, bones, and connections with the past and with the ancestors. We used threads to explore the visceral tug of the waves at high tide, and we used them in spontaneous rituals, such as 'swinging the bones' (see Section Two), 'marrying' trees, and marking the absences of wolves on the edge of Dartmoor. In response to each walk, we would make quick postcard responses - a poem, a 
drawing, a map to send back to the venue of our impending exhibition. Subsequently, we developed a practice of making successional responses to each others' makings.

As the project developed, we invited guests and groups to walk with us: an ornithologist, pagans, dancers, retired sociologists, micro-plastics scientists, housing activists, conservation volunteers, and so on. Each guest brought fresh insights to our growing understanding of the ongoing weave of the city. After our walks, we encouraged our companions to also make postal artworks in response to their experiences of the local labyrinth.

The confluence of influences, convivial interactions (our companions were chosen for their challenging expertises, walks involved symbolically relevant food and drink or ecosensual physical actions to engage with the terrain) and quickly unfolding outcomes was soon racing. Each walk explored new territory: secret, hidden and unsung places assembled before us like a cast of local characters that hitched and spliced themselves to our chosen Labyrinthine myth. Ariadne, the goddess that presided over our growing Plymouth pantheon, became triple-fold. She now sat between her sisters: Arachne (the community-weaving spider) and a Red Goddess who inverted the "scarlet woman" of the apocalyptic Book of Revelation as a female presence taking charge of her own sexuality in Stonehouse (the 'red light' district and venue for our exhibition) and manifesting as a siren warning (actual sirens are tested each Monday) of the stock-piling of decommissioned nuclear submarines by the Ministry of Defence in the heart of the city at Devonport Dockyard. The minotaur found rocky hybrid monster brothers amongst the Gogmagog giants living in caves under Plymouth Hoe, and the hulks of rotting ships became our own ruined Armada of arks sinking into the mud of Plymouth's estuaries.

This cast of characters expanded so quickly and became so complex that we wrote and published a handbook, the 'Plymouth Pantheon' (Crab \& Bee 2019). The book contained games, refrains, casts of characters and strategies for Web Walking; readers curious to find out more about Gogmagog, Ariadne and the other characters will find them in Crab \& Bee 
2019, from p.25 onwards. We created our own Plymouth Labyrinth postal service by leaving these handbooks for others to find in crevices and gaps that we had identified on previous walks, and gave out free copies during our exhibition. In three months of Web Walking, we had created an 'aesthetic ecology' (O’Sullivan 2016: 5) that included a cycle of poems, paintings, drawings, a map, games, walks and processions, ecosensual actions, a postal service, rituals and a complete Plymouth Pantheon.

Our strategy of quick creative responses spun outwards into the community: a call-out solicited over a hundred postcards, many with a red string attached. We played collaborative games of Exquisite Corpse with groups of children and teenagers, and followed Ariadne's thread in processions to the red post box to despatch the postcards that resulted. All these postcards were then exhibited as a stringy web of local, national and international connection throughout the Royal Adelaide Art and Yoga (RAAY) building where we held our exhibition. The exhibition ran across the seven spaces of the top floor of the RAAY building, a former pub and brothel. It included a shrine to Ariadne in a medicine cabinet, a Red Room with red threads radiating from an up-turned mirror on the floor and an illuminated red dress hanging in a wardrobe, and two plastic-spewing toilets as a response to our walk with microplastic experts and the vast quantities of waste we saw in the rivers and estuaries of peripheral Plymouth.

The Plymouth Labyrinth Exhibition opened with a site-specific work created by dance students from the university, and with shared 'rituals' and poetry readings. During the two weeks of the exhibition we invited people to join us for sessions of art making, and for walks around the area. The show took on its own momentum as people made and curated their own contributions, including an impressive array of invented 'extra-sensory' organs made from red or white clay. 


\section{Devices, actions and strategies}

One aspect to the 'accelerations' we both observed (and repeatedly reflected upon with each other) was a growing agility in taking small moments, images or events from our journeys and quickly spinning them out into the world as fast, light, sharable 'actions' and 'makings'. We frequently bounced these between each other, finessing them by practice, before flinging them out to others; while we moved quickly on to experimenting with new devices.

Our interdisciplinary tool kit for this devising and making included poetry, drawing, painting, playing invented games and making up rituals, and reading aloud. All this time we were continuing to make new walks; tracking in the terrain the images that had emerged in our art making and that now appeared to take on their own agency, to speak back to us. None of our material was allowed to settle or calcify, but was all the time on the move: single ideas juddering outwards, re-purposed and reassembled into new forms. For example, we spent an afternoon cutting up all our poems into short sections and then single lines on tiny pieces of paper that we then curled with scissors and flung onto the floors of the recesses of our exhibition as a 'lucky dip' of phrase-poetry for visitors. We then burnt the poetry fragments not chosen by visitors and used the ashes in ritual actions.

We generated chains of making. One such chain emerged from a walk around the china clay pits on Lee Moor, on the edge of Plymouth. After tentatively trespassing in a creamy landscape of clay with oddly exotic turquoise 'beaches' and mini-alpine ranges, we found a sheep's skeleton, disarticulated and spread over a few square metres of patchy grass. With very little discussion we spontaneously threaded vertebrae onto two lengths of woollen yarn, one red and one white. Taking the two threads at each end, we gently swung them, bones in the middle, and then whirled them around in a skipping rope motion - an impulsive and, we both remarked, very pleasurable action - leaving the red and white threads, to our delighted surprise, tightly wrapped around each other like a candy cane. 
We turned this into a game: 'The Old English Game of Crow'; for which Helen wrote a poem of instructions:

red

removed from white

by black

on green

in accordance with which she subsequently made paintings. Later we swung the bones at poetry readings and on a visit with student dancers to the former 'red light' district in the Stonehouse area of the city. This swinging action, described in the poem as a "horizontal maypole" entangling back bones, is macabre and erotic, but presented playfully as something like a playground skipping game. Influenced by the Dutch comedy TV series Jiskefet's spoofing of 'English Sports', we attempted to share the ritual qualities of these actions in as accessible and enjoyable a form as possible. Such fun, with much laughter at our own and the landscape's absurdities, has been as key a component on our walks as the intense pleasure of our hyper-sensitized presences, and we attempted to share both the intensity and the comedy in our invented games.

On the same walk on Lee Moor we found a wooden cover, in appearance like an old book; once turned over it revealed a keyhole or skull-shaped hole in the ground to a chamber in which sat a bright green frog. The mark of damp left by the hole on the wooden cover was heart shaped. Phil photographed the juxtaposition of heart and skull and, later, Helen made heart and skull frames from clay. The latter were used on the visit to Stonehouse with the student dancers described above (and later with visitors to the exhibition), taking turns to observe each other through heart and skull; framing each other in liveliness and death. 
These are two of a number of examples of roughly the same process; our experiences while walking seemed to "whizz back" at us as art works, then spin out in sharable forms. While these did not devise themselves, their devising was accompanied by a sense of 'possession', of being taken and led by the spaces and their materials and organisms (biological and spectral, and mixtures of both); this was a feeling we repeatedly discussed and, perhaps, thus reinforced. We became increasingly inclined to surrender ownership of our outputs; characterising some of them as 'fun and games' rather than artworks and disguising ourselves with various pseudonyms: Crab \& Bee, Snake \& Badger, Smoke 'n’ Mirrors, Skulk 'n' Corners. At times we became completely absorbed in our activity in a kind of flow consonant with the descriptions of Mihaly Csikszentmihalyi (1992) and when the activity was over there was a sense that we were "not the same self that existed before the flow experience" (Csikszentmihalyi 1992: 66). Perhaps the most pronounced example of this occurred in the suburb of Southway. Choosing a suburban starting point to avoid what we felt had been the too easily 'enchanted' unfolding of the previous walk along the central Plymouth waterfront, we had no sooner followed a concrete path to a playground, past a graffiti reading 'PAN', than we were tracking a stream through tall trees, climbing a scree slope and immersed in the overgrown garden of a derelict medieval farmhouse. In heavy rain, finding our way through a large expanse of levelled forest (all this in the hidden valley within the suburb) we spontaneously 'scryed' a large pool of water under cover of a tree canopy. Within three weeks we had repurposed this experience (at the same time as struggling to channel its resulting chaos) as a scrying performance to initiate an evening at a pop up night club/gallery celebrating Derek Jarman's movie 'Jubilee' (1978) curated by tactileBOSCH . During this performance we used red thread to tie the members of the audience together.

The early Southway scrying (on the second of our many walks) marked a shift in the intensity of our mode of working. After this event we often discussed the increased momentum in the 
rate of both our aesthetic responses and the depth of conviviality of our working relationship (partly a necessity for mutually supporting each other through the turmoil of what seemed like an invasion by Pan), and in our increasing openness to rushing outwards and into new developments. An increasingly immersed, reflective, fiercely-focused and yet sometimes unhinged improvisatory 'working' (in a certain alchemical sense) seemed connected to the chaotic Pan force that we had let in at Southway (at least, that is what the graffiti on the wall and the unfolding impact of the scrying had led us to believe). Until we were able to make more time and space for its demands, this force threatened to debilitate the project: its driving demand upon us creatively put at risk our equilibrium and upset the balances of our busy and separate working and domestic lives. While this force was disturbing, attention seeking and desirous, it was not an obsessive or inward-looking drive. We describe Pan as "the ultimate connector" in our 'Pantheon' handbook for the 'Plymouth Labyrinth' project and whatever we connected to at Southway continued to push us outwards, backwards and forwards at the same time, in a barely containable conviviality, to others, other spaces and other times.

The potential for an impact of extreme connectivity, when combined with a queer conviviality that involves trans-species or even trans-material interaction is evident in our dealing with missing wolves. In her 'Crossing England' research (Billinghurst 2019) Helen had noted a correlation between dwindling wildlife in an ailing landscape, and an increase in images of those same absent species in corporate and council signs and logos. This dynamic stood forward again on the north east periphery of Plymouth, at the edge of Dartmoor, where some of the last surviving wolves in the UK had been killed in the eighteenth century; the logos of Wolf Minerals surround a mine where the company (prior to its going into voluntary administration coincidental with the start of our project) had been tearing out tungsten (wolfram) from the hills. Close by, a wolf pack, its howls heard on a visit by Helen, is incarcerated at Dartmoor Zoo. 
Here, we used lengths of the red thread, chosen for its Ariadnean connectivity, to reference the hunting trajectories of the missing wolves, and the thread of empathy between predator and prey, between tracking and being tracked. Walking there on Remembrance Day for Lost Species, we tied the bright red threads to trees along paths and among abandoned cottages that are now awaiting the further, if delayed, destructive extension of the mine. We were 'trailblazing'; making a first line for the wolves' return. Climbing to the centre of an endangered copse above the tungsten pit, we made a pact with the pack of absent wolves and performed a marriage ceremony ${ }^{2}$. With a single crow above us as a witness, we made a commitment to the lost wolves of Dartmoor, tying red thread around each other's wrists, anointing each other's snouts with oil, and sharing a bottle of Wolf Beer with the earth of the copse.

"A pact with the pack:

one, two, wolf-wife for you.

two, four, wolf at my door.

three, six, red and white sticks.

four, eight, wolf at the gate."

(from Helen's poem written after the walk)

This ritual, playful and solemn, sealed a deal between us and between us and the land.

Offerings of sheep's wool and red thread were tethered around the peripheries of the site.

The following day we returned to this site with our guest, Brazilian performance artist Marilia Ennes, and repeated the improvised actions of the previous day, inviting Marilia to also make

\footnotetext{
${ }^{2}$ This action was informed by Patrica MacCormack's galvanisation to form a 'pact with the pack' as an opportunity for 'demonological activism' and for 'the philosopher to put their body where their pen is' (MacCormack 2014: online). MacCormack, in turn, is galvanised by Deleuze and Guattari's discussion of 'Becoming Animal' (Deleuze \& Guattari 1988: 29-44).
} 
a commitment to the wolves; something she would carry back with her to Sao Paulo with consequences described below. Our conviviality with Marilia included more conventional hospitalities such as her staying as a guest overnight at Helen's house, our eating dinner together and sharing stories and discussing each other's work as well as the queer ritual of sharing Wolf Rock beer and marrying wolves in the wood. Though Marilia was with us for just twenty-four hours, this was long enough to spin labyrinthine connections to another continent. Later, this ritual was re-devised and shared amongst friends (along with more imbibing of Wolf Rock beer) at the opening ceremony of our exhibition.

Each of our devices - sheep's bones and woollen threads, skull and heart frames, beer drinking and wolf-marrying - has played some part in connecting some quality or concept from the Labyrinth project to guests or participants. We have often seen these devices redeployed in others' work or lives (in their choice of materials and patterns, for example). This stickiness, this potential for transference over distance, seems in part owed to an overarching eco-sensual strategy upon and along which each of these actions has been hung. We had sought to bring our guests and visitors into intense, haptic encounters with the materials of the local ecologies through intense, attentive and reparative engagements (immersing ourselves by trespass, climbing into bramble patches and rooting around for portals).

However, while we have explained the various outputs and flingings and spinnings-out as predominantly our work, all the time we were increasingly aware of other unhuman agencies working alongside and inside (and not always harmoniously with) our own.

\section{The circumstances}

The circumstances of our walking may be its most profound agency. More than us putting one foot in front of the other; more than the in-betweenness of us moving our fascia and moving through our fascia; more than our responding reflectively or innovatively, it seemed to be the 
agencies of local ecological, agricultural, geological-industrial and edgeland spaces that did the most powerful work. They provided bones and stimulating affect for poetry writing and contributed materials, shapes and colours for paintings. Because of our practice of hypersensitisation, the landscapes were the opposite of passive backdrops or lifeless contexts, as they are often configured and narrated in signage, conservation reports or even in nature writing. Our terrains were fellow-artists, producers whose work found its ways to speak out through us.

Although they cannot speak in human voice, the fringes and vacuums around the clay pits and a precarious copse poised on the cliff top of the tungsten mine have at least been represented. There were other dynamic spaces that added to our toolkit of 'fun and games'. The bramble bushes alongside the paths of woodland near Widey Lane caught and tugged on a fifteen metre length of green thread that we had strung between us, as if some hairy 'wodwose' (an old story now little sought or seen) was trying to catch our attention. The brambles (or, perhaps, the 'wodwose'?) turned the thread from a connection between two people, to a mutual seismometer for the loneliness of nature spirits.

More generally, the entire natural logic of the city's water system has been violently disrupted and we were all the time sinking down into dry valleys from which rivers had been diverted or under which they had been buried. We saw where balancing ponds on new estates were starting to fail and pools were gathering on new roads; a water main burst, a road collapsed and an old river along the St Levan valley, now mostly covered with housing and a play area, briefly flowed again. While climate change and a massive increase in rainfall promised the return of an older more fluid dynamic, we were pleased to note how the ancient erosive carving of valleys already forced the Plymouth traffic system into repeated twists and turns, whirling Plymothians (including ourselves, trapped one night for an hour trying to drive to the pub) around and around in vortices, haunting a water no longer there, making the whole city all the time slightly giddy. 
Edgelands were crucial to our project. A relative lack of gentrification, the arrogant attitude of the city's landowners and land managers to its largely working-class populace, and the vibrancy of the materials that were here long before people, have accentuated the liminal energy of edgelands in Plymouth. While these often-littered spaces are intimidating to many, they are also opportunities for responding, uninterrupted, corporeally to effluence, excess, quarrying, fly tipping and disruptions; and to more blissful shocks and enchanting surprises. Once stepping outside the romantic norm, into material enchantment, there is plenty of grungy stuff in Plymouth that is as sensual as any sublime landscape. In such spaces walking is messy, ad hoc, and effusive; we could, and did, quickly get 'off script' there. Never quite in control, it was best when we had games or gifts in our bags, ready to be pulled out when appropriate; and if we came without these things, it was as if something there knew and was irritated by our lack of attention, and would make things uncomfortable for us.

There was a more fundamental force. We repeatedly noted the various effects of gravity; strikingly, in the collapse of sheds and fences in Southway and on outhouses of properties on the Billacombe Road. There was something serious, something grave, about these declines; all the more poignant when piqued by the undoing force of gravity's deeper non-orientation; attraction of any one mass to all others. The decline of these human-built structures could then be re-understood as a sinking together with and into organic decay, towards a reparative composture with unhuman materials and into a repurposing of the human body and its makings in the subterranean part of the forest buried under the city.

\section{Reflection}

"My desires have invented new desires, my body knows unheard-of songs" (Cixous 1976: 876).

Our work always begins outside, and with the body. We experience and think with and through the body. Hélène Cixous warns: "Censor the body and you censor breath and speech 
at the same time. Write your self. Your body must be heard" (Cixous 1976: 880). In our walking and in our making we have often found ourselves engaging with a rapturous current or flow that runs like mycelium and filament through body, mind and landscape, experientially mixing and unifying these usually separated zones in a 'dark forest' (Cixous 1976: 878) of repressed sensualities; described in Cixous's essay 'The Laugh of the Medusa' as chthonic, unconscious, sexual, female and folkloric, and to which we have threaded an actual ecological sub-forest of rhizomes and fungi. Sinking into which we have advocated, in our eco-sensual action 'Ark's Cradle'; as a composting alternative to technological flight from climate change.

Butoh dancer Alkistis Dimech describes a comparable embodied force only available through the "dark senses, touch, kinaesthesia, proprioception; or what lies below the threshold of sensory awareness" (Dimech 2016: online). To access this force, Dimech explains a process of pushing body/mind to 'the wilderness and borderlands' to encounter oneself as 'enemy, ancestor, animal, elemental force' (Dimech 2016: online); encounters we pushed ourselves to in the Plymouth edgelands. In Butoh this body/mind state is referred to as 'nikutai', meaning 'the body of flesh' or 'body of desire' and is seen as the 'vehicle for the manifestation' of the 'realm of images' (Dimech 2016: online). The images and stories that emerge out of the movement of our walking bodies are of significance to our practice and continue to work through our chains of making as we move rapidly from walk, to action, to poem, to painting, to 'world building', which Cixous describes as an act of "secretly haunting.... the elaboration of a knowledge, on the basis of a systematic experimentation with the bodily functions.... prolonged and accompanied by a production of forms" (Cixous 1976: 876). We sought to displace such an inner landscape to our terrains by writing from and with our bodies on our walks and through our world building fictions.

As these fictions were passed back and forward between ourselves, and then out into the world, their images appeared to take on their own lives, announcing their progressions and 
their affiliations to other images within each manifestation; a movement through time comparable to an action under a juddering strobe light. Our attention to wolves resurfaced in a plan by two theatre companies in Sao Paulo to re-think their city as hunting lines in the wake of the turn to reactionary politics in Brazil. Our online posting of a poem about Ariadne provoked a confessional message postcard response from Germany (addressed to Ariadne) concerning an affair conducted partly in our city.

In such ways, our looping, splicing and 'play it again' methods aligned our practice with the 'Myth-Science' of Simon O'Sullivan, who advocates a spatial and temporal 'scrambling' in order to accelerate the invoking of images or forms that appear to the practicing artists to come from 'somewhere else', but that 'also have some kind of strange relevance to the world as-it-is'. These images (and this was our experience) may appear to take on their own 'autopoietic functioning' and 'begin to recycle and re-use [their] own motifs', starting a process of 'nesting one set of fictions within another', to produce 'a certain complexity - a density' (O’Sullivan 2016: 83-4).

O'Sullivan suggests that this process could 'involve moves in a game for which one does not know the exact rules' (O'Sullivan 2016: 3-4), and certainly we were producing numerous games with ambiguous and breakable rules - 'Aye Aye Love and Die', 'Sea Kites', 'The Old Thread Game of Widey Lane' (see Crab \& Bee 2019 for details of these and other 'games') which became increasingly important as the means to and expressions of conviviality. Weird, occasionally macabre, yet inviting; the intention of these games was to engage, to put people at their ease, to introduce queer actions as welcomes rather than provocations. It was more convivial to invite people to play games with us than ask them to join in rituals.

While strategic fictioning has been employed by both of us in our separate practices, the acceleration and the increasing complexity of emergent images and story-lines that took place 
in the second half of 2018 when we began to combine our practices and to pass these fictions between each other, left us breathless. Our use of Arachne the spider and the web motif reflected our shared interest in French writer Fernand Deligny's The Arachnean and other texts. Deligny sought a new mode of human expression: one less inclined to exclusively human networks, placing the human artists or activists in a perpetually emergent web of things: 'things in movement, things and their movement, things in their movement, for things in their customary movement appear to be one and the same thing' (Deligny 2015: 97).

In our own use of webs, particularly as a means to connect to others, we drew upon Donna Haraway's ideas about 'string figuration' and 'Cat's Cradle', the playground game in which skeins of thread are passed back and forth between collaborators to make different combinations of complex and intricate patterns. Haraway sees this game as diagrammatic and transmissive and uses this image to propose ways of passing and developing knowledge; and we attempted to use this model repeatedly. "String figures are like stories; they propose and enact patterns for participants to inhabit" (Haraway 2016: 10), she says; and they, along with the web, have been useful to us as ways to describe and show how human and unhuman weave together to form our city, and to consider unhuman and human in inseparable relation to each other rather than as discrete elements.

In our relations with the unhuman, we observed in ourselves a certain 'plateauing', or 'cooling' by which desires seemed to flatten across the surface of the whole body rather than gravitate to specific culturally-prescribed points or zones. At the same time, we observed a tendency for these desires (inflected by attending to the unhuman) to disperse across immediate terrain, cosmos (which might be grossly extensive or unimaginably small) and the hyper-sensitized plateaus of the Web Walking body. This tendency towards flattening did not seem to come about as a direct act of will, but through bodily and convivial-dialogic responses to behaviours and processes that included long term walking practices with close 
attention to unhuman others, and a deferral and waiting - a 'sitting with', rather than immediately responding to embodied sensation (laughing, excitement, giddiness, breathlessness, trembling) - that resulted in a psychosomatic thinking-with-the-body that elsewhere we have described as 'sexy theory' (see Crab \& Bee forthcoming). For this thinking-with-the-body we drew on our 'pantheon' of amoral forces with which, in the form of 'places with (unhuman) personalities', we became convivial following Deleuze and Guattari's directive to "not resuscitate old myths or archaic figures" but rather to find our own equivalents to "figures of a transhistorical assemblage (neither historical nor eternal, but untimely)" (Deleuze \& Guattari 1988: 445). In accord with Donna Haraway, instead of Sky Gods we favoured Cthonic Ones, for they "are not confined to a vanished past. They are a buzzing, stinging, sucking swarm now, and human beings are not in a separate compost pile" (Haraway 2016: 55).

Parts of our accelerative 'cooling' included our use of pseudonyms, our ventriloquizing the 'voices' of the genii loci we encountered, and the close attention we paid to our unhuman companions as means to dismantle routines, "to escape the face, to dismantle the face and facializations... not by returning to animality... but by... special becomings-animal" (Deleuze \& Guattari 1988: 171), not by imitating crows or roe deer but by attending extremely carefully, non-invasively and (almost always) non-representationally to them; part of our advocacy for leaving alone and rewilding. This did not mean they left us alone; leaves turned up in our pockets, crows in our dreams and crying outside our windows: "critters are in each other's presence, or better, inside each other's tubes, folds, and crevices" (Haraway 2016: 98). We noticed how, as an apparent result of the accelerating multiplicity of our connections, sharings, embodied theorising and fictioning, we had developed something like a 'haecceity' (Deleuze \& Guattari 1988: 297); a concentrated hyper-conviviality with events, things, places, others, velocities and each other. Not as "a décor... [but as] the entire assemblage in its individuated aggregate" (Deleuze \& Guattari 1988: 289). This was not, however, an inwards 
looking concentration. It was a sprawling assembling fuelled by conviviality with others, firing an attention to attractions to others (unhuman and human) inside a radiating pattern. When we began to light fires for ourselves, we used the ash to sprinkle over a 'sun wheel' at poetry readings (a rusted dustbin lid or an engine part, symbolic of our attention, following Haraway, to the sun-in-the-ground rather than airy solar elements); in turn, the qualities of haecceity we personally experienced were closely connected to, and partly generated by, our unexpected immersion in a unique live poetry scene in Plymouth: egalitarian, marginal, rough and sophisticated in equal measure. Within a widening web, of which the poetry scene was but one part, we felt a shift from identities to events; we were abandoning aspects of ourselves to what we were doing and who we were doing it with, even to when we were doing it.

\section{Conclusion}

By means of such fictioning and 'sexy theory', as walkers in the terrain we found the terrain walking in us. Our ambulatory conversations increasingly unfolded in affordance to their context; inviting crows, rock strata and events - our regular stumbles and falls, for example to become partners. Tim Ingold proposes life as emerging along 'a meshwork of interwoven lines of growth and movement' (Ingold 2010: 3) and accordingly for us liveliness, creativity and desire are one. Like Marcus Coates we hold that "to be creative you must act" and "movement is creativity" (Coates 2016: online). For us, desire (even when cooled almost to the point of stasis) is pleasure. Patricia MacCormack describes an "ethics of desire" by which "[D]esiring bodies [that] do not seek an object, but... seek the best possible affects, those which bring joy. Liberty for the other is the joy of opening the other's capacity for expression without conditional attribution of equivalent qualities" (MacCormack 2012: 5); lines of desire 'cooling' in joyous affects.

Queer conviviality has been crucial to our nascent practice. Our collaboration as Crab \& Bee is less than a year old, at the time of writing, but conviviality has long been rooted in our 
individual walking practices; oscillating between walking alone and walking in companionship. In our collaborative projects, notably 'Plymouth Labyrinth', we have come to regard the lightness of conviviality as similar to the qualities of our small, light, quick

responses to our walks: simple actions that turn out, over time, to be of profound significance. We take conviviality seriously; we regard it not as a weak action, subordinate to collaboration, individuation, transcendence, infatuation or production, but as a slow-burning disrupter of the expected order of events. Convivialities are not dissonant with desires; rather they are part of the web that sustains and diverts and cools (red) lines of desire and which, along with (green) threads of connectivity and (white) threads of structural thinking (our own colour coding emerging from 'Plymouth Labyrinth') allows for desires, liveliness, creativity and pleasure to regenerate without addiction, territoriality or jealousy; our 'machine' for multiplying desires and (following Cixous) for inventing new ones. While there is always an element of scattering in conviviality - in sharing experiences, things and time with unhuman and human others - we have found that conviviality does not diminish either the intensity or the acceleration of our practice or the forces that vitalize it. Instead, it turns out to be both an essential part of the immersive practice of Web Walking, and a fundamental constituent of the exhibition of our work.

\section{References}

Alphandéry, Claude, et al. (2013). The Convivialist Manifesto. Accessed online at https://www.greeneuropeanjournal.eu/the-convivialist-manifesto/.

Billinghurst, Helen (2019) Ways of Making: producing artworks in the studio in response to experiential walking. (PhD thesis) Accessed online at https://pearl.plymouth.ac.uk/handle/10026.1/13656

Cixous, H. (1976). The Laugh of the Medusa. Journal of Women in Culture and Society, 1 (4), 875-893. 
Coates, M. (2016) Creative Fitness. Accessed online at http://www.marcuscoates.co.uk/projects/99-creative-fitness

Crab \& Bee (Billinghurst, H. \& Smith, P.) (2019). Plymouth Pantheon. Accessed online at https://onedrive.live.com/?authkey=\%21AKlzgBl\%5FK7jr3FI\&cid=079FE8504A680033\&id $=79$ FE $8504 \mathrm{~A} 680033 \% 213282 \&$ parId=79FE $8504 \mathrm{~A} 680033 \% 212158 \& \mathrm{o}=$ OneUp

Crab \& Bee (Billinghurst, H. \& Smith, P) (forthcoming) The Pattern. Charmouth: Triarchy Press.

Davis, E. (2019). High Weirdness. London \& Cambridge (Mass.): Strange Attractor/MIT Press.

Deleuze, G. \& Guattari F. (1988). A Thousand Plateaus. (Translated by Brian Massumi.) London/New York: Continuum.

Deligny, F. (2015). The Arachnean and Other Texts. (Translated by Drew S. Burk \& Catherine Porter.) Minneapolis: Univocal Publishing.

Dimech, A. (7 May 2016). Dynamics of the Occulted Body'. https://scarletimprint.com/essays/dynamics-of-the-occulted-body

Haraway, D. J. (2016). Staying With The Trouble. Durham \& London: Duke University Press. Harris, Dave. ( 20 Feb 2016). Deleuze for the desperate \#3: haecceity. Accessed online at http://www.arasite.org/deltranscript3haecc.html

Ingold, T. (1 Jul 2010). Bringing Things to Life: Creative Entanglements in a World of Materials. Accessed online at http://eprints.ncrm.ac.uk/1306/1/0510_creative_entanglements.pdf MacCormack, P. (2012). Post-human Ethics. Farnham: Ashgate. Nicolai, O. \& Wenzel, J. (2012). Labyrinth. Zurich: Spector Books \& Rollo Press. O'Sullivan, S. (2016). Myth-science and the Fictioning of Reality. Paragrana, 25 (2), 80-93. 